\title{
Integral approach to assessing the criticality of railway infrastructure elements
}

\section{David Rehak* and Simona Slivkova}

Faculty of Safety Engineering,

VSB - Technical University of Ostrava,

Lumirova 13, 70030 Ostrava, Czech Republic

Email: david.rehak@vsb.cz

Email: simona.slivkova@vsb.cz

*Corresponding author

\section{Radim Pittner}

Czech Railway Infrastructure Administration, Department of Safety and Crisis Management, Dlazdena 1003/7, 11000 Prague, Czech Republic

Email: pittner@szdc.cz

\section{Zdenek Dvorak}

Faculty of Security Engineering, University of Žilina, 1. Maja 32, 01026 Žilina, Slovak Republic

Email: zdenek.dvorak@fbi.uniza.sk

\begin{abstract}
In the last ten years, considerable attention has been paid to analysing and assessing the criticality of railway infrastructure elements. Publications on the subject mostly assess elements only from a certain point of view, such as purpose, reliability or risk. This leads to only a partial assessment of criticality without continuous correlation, which may result some critical elements of the system being omitted. The article introduces the railway infrastructure criticality assessment tool (RICA tool), which was created to evaluate the criticality of railway infrastructure elements in all aspects. The integral approach of the tool lies in comprehensively assessing the technical and process factors of rail transport. The criticality of railway infrastructure elements is therefore assessed not only in terms of the relevance and resilience of elements but also their interdependence, substitutability, risk and impact.
\end{abstract}

Keywords: railway infrastructure; criticality assessment; integral approach; RICA tool; technical and process factors.

Reference to this paper should be made as follows: Rehak, D., Slivkova, S., Pittner, R. and Dvorak, Z. (2020) 'Integral approach to assessing the criticality of railway infrastructure elements', Int. J. Critical Infrastructures, Vol. 16, No. 2, pp.107-129.

Biographical notes: David Rehak is a $\mathrm{PhD}$ in Processes Modelling and Simulation of Troops and Population Protection at the University of Defence. $\mathrm{He}$ is currently an Associate Professor at the VSB - Technical University of 
Ostrava, Faculty of Safety Engineering. His scientific and research work is aimed on critical infrastructure resilience and protection, civil protection and risk management. He is a member of the International Association of Critical Infrastructure Protection Professionals (IACIPP) and Editor-in-Chief of the Transactions of the VSB - Technical University of Ostrava, Safety Engineering Series (TSES).

Simona Slivkova is a PhD in Fire Protection and Safety at the VSB - Technical University of Ostrava, Faculty of Safety Engineering. She is currently an Assistant Professor at the same university. Her scientific and research work is aimed on crisis management, critical infrastructure and criticality of elements. She is also interested in the critical infrastructure of rail transport and the reliability of transport.

Radim Pittner is an MSc at the University of Pardubice, Faculty of Transport Engineering. He is currently a member of the Department of Safety and Crisis Management, part of the General Directorate of the Czech Railway Infrastructure Administration. He focuses on ensure the continuity of the organisation, on protect of critical transport infrastructure elements and on compliance the safety requirements of rail transport.

Zdenek Dvorak is a PhD in Military Transport at the Military Faculty of the University of Transport and Communications. He is currently a Professor at the University of Zilina, Faculty of Security Engineering. His scientific and research work is aimed on critical infrastructure protection, information support of civil protection and risk management. Actually, he is a member of seven Scientifics Boards in Czech and Slovak universities. Long years, he is a member of Scientific Committees on international conferences in Bulgaria, Czech Republic, Poland, Republic of Lithuania, Serbia and Slovak Republic. $\mathrm{He}$ is currently the guarantor of the study program - Security and Protection of Critical Infrastructure. He has a long-term experiences with solving national and international research and scientific projects.

\section{Introduction}

Rail transport is one of the most important modes of transport on land for people and freight. Its importance is emphasised, inter alia, under the North Atlantic Treaty Organisation (NATO), in which it forms one of the supporting means of transport for armed forces (Vlkovsky et al., 2017). Because of their importance and high impact at a social, economic, psychological and political level, transport systems are often key targets for terrorist attacks (Hedel et al., 2018). Based on the above, rail transport was included in the European Critical Infrastructure sectors in 2008 (European Council, 2008). In the following period, EU member states began identifying and determining the various elements of railway critical infrastructure at European and national levels (Rehak et al., 2016). The results of the assessment showed that in addition to elements of critical infrastructure, some elements did not meet the defined cross-sectoral and sectoral criteria in railway infrastructure but were key or even critical to the region (Slivkova et al., 2018). These elements must be appropriately identified, and their criticality evaluated in order to adopt adequate security measures (Leitner et al., 2017). 
Current research provides a series of approaches to identifying critical elements. These approaches are not only of a general nature but also focus specifically on transport. General approaches are aimed either at systemic determination of infrastructure criticality (e.g., Katina and Hester, 2013) or at assessing the criticality of elements in different types of infrastructures by using a variety of factors. These factors include the possible impact of an element's failure on the assessed system (e.g., Jönsson et al., 2008; Luiijf et al., 2003), the dependence of the monitored element (e.g., Fekete, 2018; Rinaldi et al., 2001), the significance of the element (e.g., Alsubaie et al., 2015; Zhang et al., 2015), the vulnerability of the element (e.g., Pant et al., 2016; Theoharidou et al., 2009) and risks in relation to the element of interest (e.g., Dvorak et al., 2017; Pant et al., 2015; Sousek and Dvorak, 2013). Another important factor is assessing the criticality of elements from the perspective of the attacker, whose aim is to disconnect a network at a number of critical nodes and disrupt the connection of individual key components to other elements (Faramondi et al., 2016). A similar approach is assessing criticality by considering the risk of terrorist attack with the aim of optimally allocating limited resources for protection (Norkin et al., 2018). Most general approaches are usable as suitable input for an integral approach design to assess the criticality of railway infrastructure elements, but their direct use in such assessment is not possible.

By contrast, specific approaches are already based on the assessment of transport elements, but always from a certain point of view, which makes it impossible to achieve an integrated assessment. These approaches include, for example, identifying critical elements by calculating the increased cost of disruption to or delay in the element (Bababeik et al., 2017; Khaled et al., 2015). Assessing elements in terms of railway transport renewal according to a multi-criteria analysis of the financial, economic and environmental domains is a similar approach (Caetano et al., 2018). Another specific approach is assessing the importance of a given element (i.e., performance or category) or its importance arising from the possibility of an alternate route or the likelihood of occurrence of an adverse event (Leitner et al., 2017). Another aspect not to be overlooked is identifying critical sites based on reliability analyses (Fourie and Zhuwaki, 2017), analyses of expected accident data (Striegler et al., 2012) or analyses of the vulnerability of interdependent technical infrastructures (Johansson et al., 2011).

Based on the analysis performed it can be stated that these approaches are functional (although their application in most cases is difficult and/or difficult to comprehend) but they do not facilitate an integral assessment of elements, which is required for comprehensive assessment (CRIA, 2016). Against this background, the article introduces the railway infrastructure criticality assessment tool (RICA tool), which was developed to assess the integrity of critical infrastructure elements. The purpose of this assessment tool is to identify the critical railway infrastructure elements in a given territory for which measures can be subsequently established to ensure the preparedness or enhancement of resilience of designated elements (e.g., Rehak et al., 2018; Stoller et al., 2018; Klein and Hutter, 2017; Hromada and Lukas, 2012; Dvorak et al., 2013).

Criticality in the context of this article is seen as the relative measure of importance and meaning of a given element that also expresses the vulnerability of the element and the possible negative effects of its failure with regard to the links in the system. The integral approach of this tool lies in comprehensively assessing the technical and process factors of rail transport. The criticality of railway infrastructure elements is thus assessed not only in terms of the relevance and resilience of elements but also includes an assessment of their interdependence, substitutability, risks and impact. 


\section{Key factors determining and influencing criticality assessment}

In general, any system can be comprehended as a group of interconnected and interactive elements that fulfil clearly defined tasks with varying material levels. The functioning of such a system is determined and influenced by a number of factors. Technical factors (i.e., infrastructure) and process factors are key factors that determine or affect system processes (Rehak et al., 2018). In the rail transport system, process factors include rail transport operators, transport processes, infrastructure links, active threats to the system and the impact of disturbing that system.

\subsection{Technical factors}

The basis of secure and high-quality rail transport is reliable infrastructure. It consists of railway estates, railway bodies, switches, other engineering constructions (e.g., bridges, tunnels and railway crossings) and associated station infrastructure (e.g., platforms, railway signals). These railway infrastructure elements are classified in three groups according to their topological structure, namely line elements (LEs), point elements and areal elements (AEs) (Rehak et al., 2019; Fekete, 2018).

LEs provide transfer, delivery or transport between two physically separate locations (i.e., connectors of individual elements/locations). They are a meaningful basic group in relation to all point and AEs. In railway transport, LEs are the individual lines.

PEs are closed units that fulfil their function for the needs of a particular LE. Mainly, these are locally defined points based in a small area. The PE can also work for several LEs (e.g., a diverging set of switches, diamond crossing with slips). Inside the railway infrastructure area, PEs are primarily railway equipment (e.g., communication equipment, railway signals, electrical equipment, signalling systems, switch systems), track construction, railway crossings and halts.

AEs are characterised as a whole unit and include places where multiple point and LEs can work simultaneously and where the very existence of so many elements in one place can be critical. AEs are the most complex group of elements, consisting of at least two PEs and at least one LE. In AE, the effects of an outage can accumulate. Mainly railway junctions, crossing protections and railway stations with railway signals form this type of element.

\subsection{Process factors}

An important variable in an integral assessment of the criticality of railway infrastructure elements are process factors. These factors partly determine, but primarily influence, the level of relevance and resilience of the assessed elements in the rail transport system. By integrating them into the assessment process, more accurate and comprehensive results are obtained on the criticality of each element and their interdependence. An overview of the process factors determining and influencing the criticality assessment of railway infrastructure elements is presented in Figure 1.

Each system is determined and simultaneously influenced by entities that either produce or use the service within that system or affect its operation in other ways (e.g., an authorised representative of the given system). Each of these entities enters the rail system with a different target and role in terms of the functioning of the entire system. The most important entities determining or affecting the railway system include: 
- a managing authority (i.e., the Ministry of Transport) - function as an authorised representative in the transport sector

- inspection and investigative bodies (i.e., access to transport infrastructure authority, state rail authority, railway inspectorate) - regulatory, controlling or investigative functions in the transport sector

- $\quad$ rail operators - fulfilment of obligations, such as ensuring railway serviceability and safety, maintaining and repairing railways, or modernising and developing rail transport routes

- $\quad$ rail transport operators - operation of rail transport as a subject of business

- $\quad$ transport order parties (i.e., freight forwarders and passengers in passenger transport) - may have service requirements (transport) such as time, safety or qualitative requirements, require provision of transport services in a given territory.

The above-mentioned requirements of some rail transport operators may coincide at a certain point. The basic requirements of these entities are presented in Table 1.

Transport as such is strongly determined by transport processes that, in common harmony and logical continuity, contribute to the proper functioning of the whole system. Individual railway transport processes are a key foundation for fulfilling expected rail transport functions. Processes in rail transport can be divided into local processes for securing traffic in stations and network processes for securing traffic in the railway network (Gasparik and Kolar, 2017). Traffic security (transport safety), track management, rail transport organisation (shifts, delays, overtaking, etc.) and emergency measures (Ministry of Transport, 2013) are most often applied in the field of transport processes (Ministry of Transport, 2013).

Figure 1 Process factors determining and influencing criticality assessment

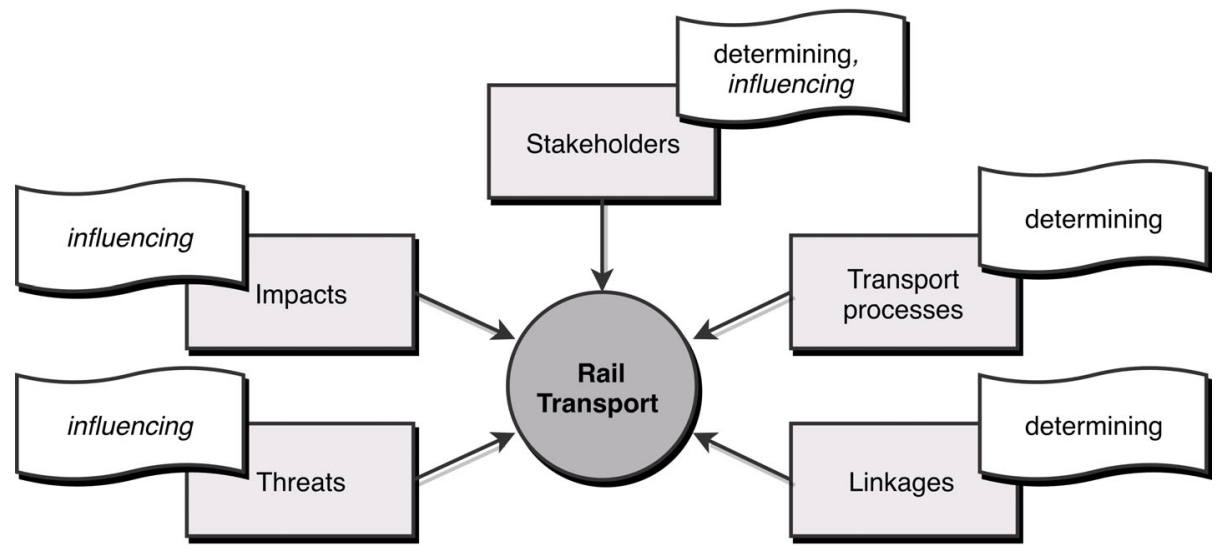

Another important determinant of each system is its linkages, which can be physical, cyber, related to geographic, or logical in nature (Rinaldi et al., 2001). The most important physical linkage in the rail transport system is the dependence of railway infrastructure elements on the supply of electricity. The most important cyber linkage considered can be the transmission of traffic management data and operation of transport systems (e.g., railway signals). Geographical linkages can be seen in terms of 
the territorial distribution of individual lines and stations to provide connections and ensure transport serviceability of the region. The most important logical linkage in rail transport can be seen in the relationship between the rail operator and the rail transport operator. Without logical cooperation between these entities, rail transport could not take place.

Table 1 Basic requirements of rail transport operators

\begin{tabular}{lccccc}
\hline & $\begin{array}{c}\text { Managing } \\
\text { authority }\end{array}$ & $\begin{array}{c}\text { Railway } \\
\text { operators }\end{array}$ & $\begin{array}{c}\text { Railway freight } \\
\text { operators }\end{array}$ & $\begin{array}{c}\text { Transport } \\
\text { order parties }\end{array}$ & Regions \\
\hline Safety & $\mathrm{X}$ & $\mathrm{X}$ & $\mathrm{X}$ & $\mathrm{X}$ & $\mathrm{X}$ \\
Logic system & $\mathrm{X}$ & $\mathrm{X}$ & $\mathrm{X}$ & $\mathrm{X}$ & $\mathrm{X}$ \\
Smoothness & $\mathrm{X}$ & $\mathrm{X}$ & $\mathrm{X}$ & $\mathrm{X}$ & \\
Transport service & $\mathrm{X}$ & & $\mathrm{X}$ & $\mathrm{X}$ & $\mathrm{X}$ \\
Modernisation & & $\mathrm{X}$ & $\mathrm{X}$ & $\mathrm{X}$ & \\
Profit & & $\mathrm{X}$ & $\mathrm{X}$ & & \\
Competitiveness & $\mathrm{X}$ & & & & $\mathrm{X}$ \\
\hline
\end{tabular}

The final group of process factors affecting the functionality of rail transport systems are systemic threats and the impacts arising from disruption of the system. Systemic threats can be classified from different perspectives - internal and external threats, anthropogenic and naturogenic threats, deliberate and unintentional threats, etc. It is also possible to assess the risk factor of rail transport from the information concerning accidents in this sector (Maalel et al., 2014). In the context of these threats, it is necessary to define all risks, especially for the following areas of the railway system: transport processes, transport system, rail transport management, transport infrastructure and railway guided vehicles (Dvorak et al., 2010). The system is also heavily impacted by disruption to critical elements (e.g., Luskova et al., 2015). These disruptions may subsequently affect railway transport operators (e.g., financial loss, time delays for the order party, etc.), transport processes (e.g., delays or complications in organising rail transport), related infrastructure (e.g., violation of the functionality of dependent elements) or the functionality of links (e.g., supply restrictions, need for substitute resources).

Defining the key technical and process factors that determine and influence criticality assessments forms the methodological basis for assessing the criticality of railway infrastructure elements. From this methodological basis, a tool for integral assessment of the criticality of these elements can be created.

\section{Railway infrastructure criticality assessment - RICA tool}

The RICA tool was developed primarily for the needs of the most important rail operator in the Czech Republic (i.e., the Czech Railway Infrastructure Administration) and its security staff in individual regional directorates. It meets the primary requirements of this operator in regard to comprehensiveness, clarity, ease of applicability (Slivkova et al., 2018) and its assessment capabilities (primarily based on available data). Other entities, however, such as rail transport operators and freight forwarders, can also use this tool in the Czech Republic or abroad. 
The RICA Tool assesses elements from the bottom-up. First, LEs (individual tracks) are assessed as the basic components of the railway, followed by PEs as a complement to LEs and finally AEs as special sites along the railway line. Assessing the elements is performed macroscopically: for the purposes of assessment, elements are simplified and made into integrated components.

The input necessary for correct application of the criticality assessment process using the RICA Tool were developed within the framework of the railway infrastructure elements assessment system (Slivkova et al., 2018). The framework integrates individual elements of railway infrastructure, rail transport stakeholders, transport process requirements, legal requirements, technical standards and internal guidelines as well as basic methodology.

\subsection{The criticality assessment process}

The RICA Tool is a critical assessment process whose output is the basis for identifying critical railway infrastructure elements and their subsequent protection (Figure 2). This process consists of three ordered sub-processes to provide continuity in evaluation.

Figure 2 Sub-processes of the critical infrastructure criteria assessment process

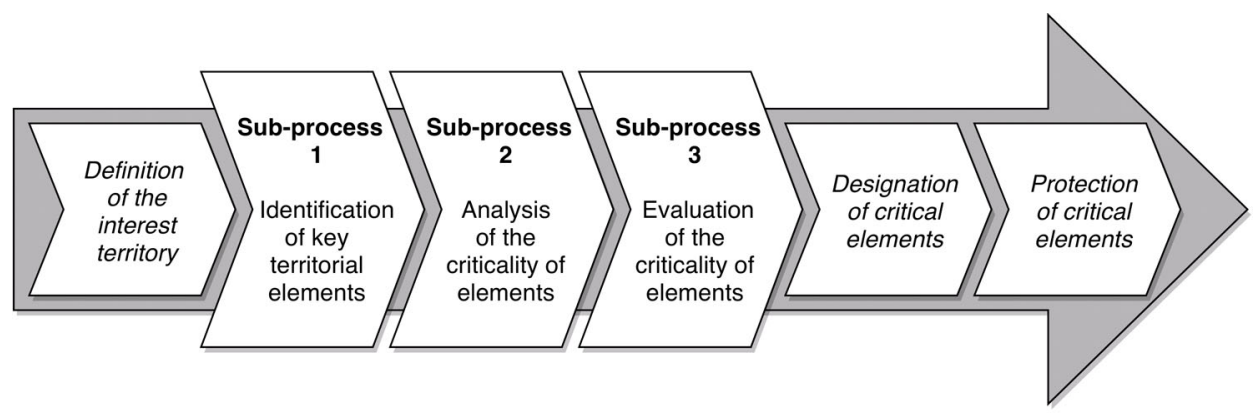

\section{Sub-process 1: identification of key territorial elements}

In any defined area it is necessary to identify all the key infrastructure elements, such as transport management elements (e.g., transport control systems), safety elements (e.g., signals) and elements difficult to replace (e.g., tunnels, bridges). These elements are then classified according to three groups: line, point and AEs (Rehak et al., 2019; Fekete, 2018).

\section{Sub-process 2: analysis of the criticality of elements}

Analysis of the criticality of railway infrastructure elements in a defined area takes place in three ordered stages:

1 analysis of the criticality of LEs

2 analysis of the criticality of PEs

3 analysis of the criticality of AEs. 
The criticality assessment criteria are defined for each stage, for which detailed descriptions are presented below. Each key element identified within a given group must be assessed in the given stage.

The critical analysis consists of five steps:

1 data collection for the requirements of individual criteria

2 determination of simple criticality (i.e., transformation of the data obtained into a uniform assessment scale according to each criteria)

3 preferential consideration of the significance of the given criteria using weighted coefficients

4 determination of the weighted criticality of elements

5 determination of the resultant criticality of elements.

The weighted coefficients are determined according to the expert assessment of the rail operator (i.e., the Czech Railway Infrastructure Administration) using the pairwise comparison method. The resultant normalised weight values are presented as a part of the presentation of individual criteria for line, point and AEs. By its very nature, the expert assessment and its derived scales will always be somewhat subjective. However, given that intense research is still ongoing in this area, no widely accepted hierarchy of items is available.

Weighted criticality is determined according to the equation (1):

$$
W C_{i C}=S C_{i C} \cdot w_{c}
$$

where $W C_{i C}=$ weighted criticality of $i^{\text {th }}$ element for the $C^{\text {th }}$ criterion [\%], $S C_{i C}=$ simple criticality of $i^{\text {th }}$ element for the $C^{\text {th }}$ criterion [\%] and $w_{C}=$ the weighted coefficient of the $C^{\text {th }}$ criterion.

The resultant criticality is determined according to the equation (2):

$$
F C_{i}=\sum_{C=1}^{n} W C_{i C}
$$

where $F C_{i}=$ the final criticality of the $i^{\text {th }}$ element [\%] and $W C_{i C}=$ the weighted criticality of the $i^{\text {th }}$ element for the $C^{\text {th }}$ criterion [\%].

\section{Sub-process 3: evaluation of the criticality of elements}

Final evaluation of criticality is based on comparing the resultant values of the analysed elements to the defined reference criticality values. A clearly defined borderline level is a crucial step in correctly identifying critical elements (Luiijf et al., 2003; Celko and Dvorak, 2018). The borderline level of criticality to determine critical elements is specified in four categories according to the scale of impact arising from disturbing or failure of the function of the element under evaluation. These values are set out and explained in the following sections.

\subsection{Criteria for assessing elements of criticality}

An important part of the process in identifying critical elements is defining and correctly establishing the assessment criteria, primarily according to the rail operator's 
requirements. These criteria are created for each set of elements, i.e., LEs, point elements (PE), and AEs. Their different significance is considered using weighted coefficients. Because of the different units of expression in the natural values of the criteria, these values are converted into a uniform rating scale, which is expressed as a percentage (so-called simple criticality value).

\subsubsection{Criteria for analysing the criticality of LES}

The specific criteria for assessing criticality in the first stage considers the significance of the railway (criterion L1 with a weight of 0.1), transport performance (criterion L2 with a weight of 0.4 ), the possibility of an alternative route (criterion L3 with a weight of 0.3 ) and track risks (criterion L4 with a weight of 0.2).

The significance of the track (L1) is primarily based on the category of railway to which the LE belongs. Railway categories are defined according to the Common Safety Methods (Agency for Railways, 2016) as:

- international corridors and national railways (100\% simple criticality)

- regional railways ( $90 \%$ simple criticality)

- $\quad$ sidings ( $50 \%$ simple criticality)

- $\quad$ local, testing and special tracks ( $0 \%$ simple criticality).

From the point of view of the railway operator, the national and regional railways are of the utmost importance and primarily provide transport services to the state and region. However, when assessing simple criticality, the fact that national railways are also of international importance must be considered. For these reasons, national railways are rated at a simple criticality of $100 \%$ and regional rail at $90 \%$. Sidings are only relevant to the rail operator to meet the needs of the national economy (sidings connect some companies to regional and national railways). According to these factors, sidings are assigned a simple criticality of $50 \%$. Local railways, testing and special tracks have zero significance to the Czech Railway Infrastructure Administration.

The second criterion for assessing the criticality of a LE is transport performance on a monitored track (L2). Performance under this criterion is assessed by the number of freight and passenger transports on a given rail path per unit of time, which is known as the 24-hour carrying capacity of the track. The values of simple criticality of this criterion are reflected in the performance of the most efficient track of the regional headquarters, which is rated $100 \%$. Compared to the performance of the most efficient track, the simple criticality of other rated tracks can be determined as a ratio of their performance (e.g., half performance will be rated at 50\%).

Another criterion is the possibility of replacing the failure of the observed element (L3), that is, the possibility of an alternative route. From the point of view of the rail operator, the use of an alternative route is primarily assessed in this criterion. The values of the simple criticalities therefore correspond to these conditions:

- the monitored track has an alternative route that corresponds to the parameters of the section requiring by-pass - simple criticality $=0 \%$

- the monitored track does not have an alternative route (i.e., carriers must use alternative road transport in the event of track failure) - simple criticality $=100 \%$. 
An important step in analysing the criticality of LEs is a risk assessment of the given track and related equipment (L4). A risk assessment of the track primarily corresponds to the sections monitored by the Czech Railway Infrastructure Administration that have a frequent occurrence of major emergencies. Specific risks include:

- damage to tracks because of floods

- damage to tracks because of special floods

- $\quad$ emergency because of snow on tracks

- landslides on tracks

- fallen trees on tracks

- leakage of hazardous substances on the track circuit

- damage to tracks because of heat.

Risk rates for each of the above-defined events must be expressed for the monitored track. For this purpose, the failure mode, effects and criticality analysis method (IEC, 2006) can be applied. The resulting value of the simple criticality of the element in this criterion is represented by the percentage expression of the sum of all risks applicable to the element up to the maximum possible sum of the risk levels.

\subsubsection{Criteria for analysing criticality of point elements}

The specific criteria for assessing criticality in the second stage takes into account the criticality of LEs (criterion P1 with a weighted preference of 0.1 ), the influence and dependence of the element (criterion P2 with a weighted preference of 0.4), the substitutability of the element (criterion P3 with a weighted preference of 0.3 ), and the risks for the element (criterion P4 with a weighted preference of 0.2).

The first criterion in evaluating a point element is the criticality of the LE (P1). This criterion reflects the fact that increasing the criticality of a LE increases the level of criticality of the point element. In this criterion, the value of the resultant LE criticality where the observed element fulfils its function is transferred to the point element assessment (the value of the resultant criticality of the LE corresponds to the value of the simple criticality of the point element for this criterion).

The criterion of the influence and dependence of element (P2) takes into account all the elements that are dependent on the observed point element (so-called dependent elements) and all the elements that could, by contrast, influence the observed element (the so-called influential elements). An assessment of the simple criticality of a given element is then performed according to Table 2.

The substitutability criterion (P3) considers the possibility of replacing the observed element with another element without any significant loss of system function, or the possibility of providing a substitute element. The values of the simple criticalities of individual point element types correspond to the option of replacing an observed element with another element, or with a substitute solution that fulfils the missing feature of an element. An element that cannot be replaced in any way is rated at a simple criticality of $100 \%$. Conversely, an easily replaceable element acquires a simple criticality of $0 \%$. The specific values of the simple criticalities of substitutability from the track operator's point of view for individual point element types are defined in Table 3. 
Table 2 Matrix for assessing the simple criticality of $\mathrm{P} 2$ criteria

\begin{tabular}{|c|c|c|c|c|c|}
\hline \multirow{8}{*}{ 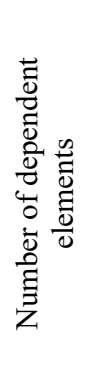 } & 6 & $70 \%$ & $80 \%$ & $90 \%$ & $100 \%$ \\
\hline & 5 & $60 \%$ & $70 \%$ & $80 \%$ & $90 \%$ \\
\hline & 4 & $50 \%$ & $60 \%$ & $70 \%$ & $80 \%$ \\
\hline & 3 & $40 \%$ & $50 \%$ & $60 \%$ & $70 \%$ \\
\hline & 2 & $30 \%$ & $40 \%$ & $50 \%$ & $60 \%$ \\
\hline & 1 & $20 \%$ & $30 \%$ & $40 \%$ & $50 \%$ \\
\hline & 0 & $10 \%$ & $20 \%$ & $30 \%$ & $40 \%$ \\
\hline & & 1 & 2 & 3 & 4 \\
\hline
\end{tabular}

Table 3 Values of the simple criticalities for the P3 substitutability criterion

\begin{tabular}{lc}
\hline Point elements & Values of simple criticalities \\
\hline Traffic control workplaces & $100 \%$ \\
Track constructions & $100 \%$ \\
Electrical equipment & $100 \%$ \\
Electro-dispatching workplaces & $100 \%$ \\
Station signals & $90 \%$ \\
Track signals & $90 \%$ \\
Telecommunications equipment & $90 \%$ \\
Operating control posts without station signals & $80 \%$ \\
Railway crossing signals & $50 \%$ \\
Switching systems & $50 \%$ \\
Halts & $20 \%$ \\
Railway crossings without crossing signals & $10 \%$ \\
\hline
\end{tabular}

Finally, each point element is subjected to the element risk criterion (P4). This criterion follows the LEs criticality analysis criterion L4 - Track risks. In this identification process, risks that have already been assessed in relation to the line track on which the monitored element fulfils its function can be omitted. Specifically, the following risks are involved:

- damage to equipment because of a fire on the track circuit

- damage to equipment because of material defects

- damage to equipment caused by traffic accidents

- damage to equipment caused by incorrect train movements

- $\quad$ emergency caused by failure in control technology

- theft of or sabotage to track equipment.

Assessing the element's simple criticality rating in this criterion is based on the same approach as in LE criticality L4 - track risks, with different possible events. 


\subsubsection{Criteria for analysing the criticality of AEs}

The specific criteria for assessing criticality in the third stage takes into account the criticality of LEs (criterion A1 with a weighted preference of 0.3 ), the criticality of point elements (criterion A2 with a weighted preference of 0.4 ), the complexity of elements (criterion A3 with a weighted preference of 0.1 ) and the option of alternative routes (criterion A4 with a weighted preference of 0.2).

The first criterion for assessing the criticality of LEs is A1. Each LE relates to at least one linear element whose increasing criticality increases the criticality of the AE.

When a LE is a single LE, the value of the simple criticality of this criterion is the value of the resultant criticality of the LE. If the LE consists of several LEs, the value of the criticality of this criterion is the value of the resultant criticality of the LE that has the highest final criticality (the criticality value of the most critical LE corresponds to the criticality value of the $\mathrm{AE}$ for this criterion).

The criticality of point elements (A2) takes into account all the point elements that make up the assessed AE. The criticality of point elements expresses the criticality of at least two point elements. The value of the simple criticality of this criterion is the weighted average of the resultant criticality values of all point elements that fulfil the function in the given AE. The weights are determined by the number of dependent elements in relation to the element under observation.

The complexity of the AE (A3) reflects the fact that increasing complexity can increase the criticality of a given element. The assessment corresponds to the simple criticality values derived in consultation with the track operator:

- if the element consists of no more than 5 point and LEs $=20 \%$

- if the element consists of 6 point and LEs $=40 \%$

- if the element consists of 7 point and LEs $=60 \%$

- if the element consists of 8 point and LEs $=80 \%$

- if the element consists of 9 point and LEs $=100 \%$.

The criterion of the alternative route option (A4) follows the L3 criterion, which is the option of an alternative route based on the LEs analysis. However, in this case, it is the strategic placement of the $\mathrm{AE}$ in the rail system of a given region or territory that is assessed. From the point of view of the track operator, this criterion primarily evaluates the possibility of an alternative route in AE. The simple criticality values therefore correspond to the following conditions:

- the observed AE has an alternative route matching the parameters of the by-passed section - simple criticality $=0 \%$

- the observed AE does not have an alternative route (i.e., carriers must use road transport in the event of a failure) - simple criticality $=100 \%$.

\subsection{Referential values of criticality}

In the final stage of assessing the criticality of railway infrastructure elements, the derived criticality element values must be compared to the reference values (Table 4), 
which then allows elements to be classified according to four categories. The first two categories include elements that are still considered key elements, since their disruption or malfunction would only result in disruption to the flow of traffic. The other two categories include critical elements whose disruption or malfunction would result in halting traffic.

Table 4 Reference values for assessing the criticality of railway infrastructure elements

\begin{tabular}{|c|c|c|}
\hline Interval & Category & Impact \\
\hline$(81 ; 100)$ & $\begin{array}{l}\text { Critical elements } \\
\text { of category } 1\end{array}$ & $\begin{array}{l}\text { Disturbance or failure of the function of elements in this } \\
\text { category would result in halting traffic in several regions. }\end{array}$ \\
\hline$(62 ; 81)$ & $\begin{array}{l}\text { Critical elements } \\
\text { of category } 2\end{array}$ & $\begin{array}{l}\text { Disruption or failure of the function of elements in this category } \\
\text { would result in halting traffic in the region concerned. }\end{array}$ \\
\hline$(43 ; 62)$ & $\begin{array}{l}\text { Key elements of } \\
\text { category } 1\end{array}$ & $\begin{array}{l}\text { Disturbance or failure of the function of elements in this } \\
\text { category would result in disruption to the flow of regional } \\
\text { traffic. }\end{array}$ \\
\hline$(0 ; 43)$ & $\begin{array}{l}\text { Key elements of } \\
\text { category } 2\end{array}$ & $\begin{array}{l}\text { Disturbance or failure of the function of elements in this } \\
\text { category would result in disturbing the flow of local traffic. }\end{array}$ \\
\hline
\end{tabular}

The breakdown of criticality levels and establishment of reference values given in Table 4 is based philosophically on the Failure Mode, Effects and Criticality Analysis (IEC, 2006), which uses multiple variables to determine risk level and is based on the extreme values of variations in an assessment of their statuses. Similarly, different levels of criticality have been established that take into account extreme values (i.e., 1 and 4 ) in the cases of four criteria:

- $1,1,1,4=>\varnothing 1.75=>43.7 \%$

- $1,1,4,4=>\varnothing 2.50=>62.5 \%$

- $1,4,4,4=>\varnothing 3.25=>81.2 \%$

- $4,4,4,4=>\varnothing 4.00=>100 \%$

First, attention should be given to the critical elements of I and II whose disruption or malfunction would result in halting traffic. Specifically, it should involve defining and implementing adequate safety measures to ensure the preparedness or enhanced resilience of designated elements (e.g., Rehak et al., 2018; Stoller et al., 2018; Klein and Hutter, 2017; Hromada and Lukas, 2012; Dvorak et al., 2013).

\section{Example of a practical RICA tool application}

For a practical demonstration of the proposed railway infrastructure criticality assessment (RICA tool), a case study was prepared. This study focused on the assessment of critical elements in the section between Břeclav and Podivín, located in south-eastern Czech Republic. The underlying data was provided by the rail operator, i.e., the Czech Railway and Transport Administration. 
The area of interest is the line section between the towns of Břeclav and Podivín (Figure 3). The section is on line number 250 and is $11 \mathrm{~km}$ long. The owner of this line is the Czech Railway Infrastructure Administration.

Figure 3 The assessed line section between Břeclav and Podivín (see online version for colours)

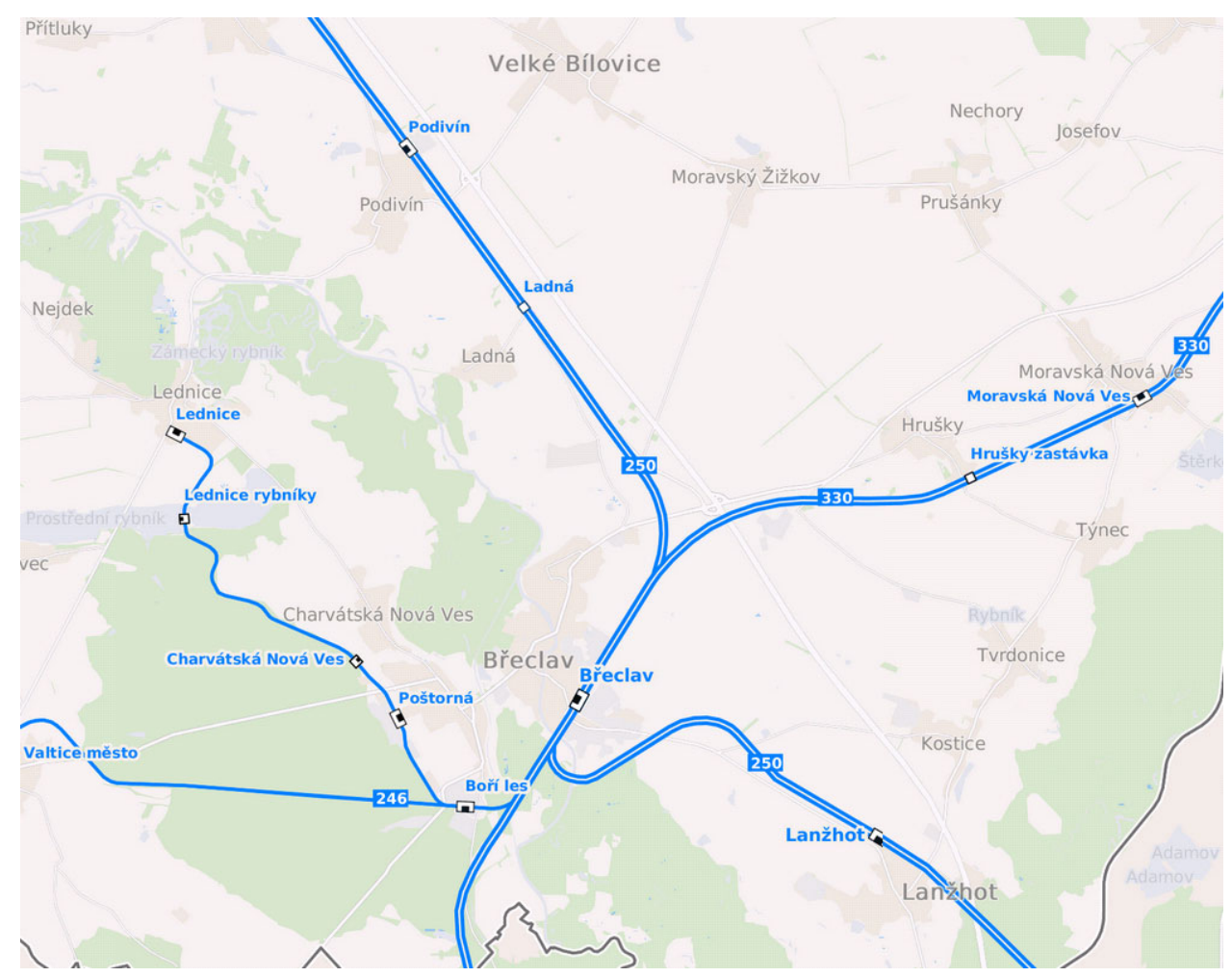

Source: Czech Railways (2018)

\section{Sub-process 1: Identification of key elements}

The following key elements were identified at the designated line section:

1 Line elements:

- Břeclav - Podivín intermediate section (LE1)

2 Point elements:

- Břeclav station signals (PE1)

- Břeclav station territory track signals (PE2)

- Břeclav station traffic control workplace (PE3)

- Břeclav station switching systems elements (PE4)

- Břeclav station telecommunications elements (PE5) 
- Břeclav station electrical equipment elements (PE6)

- $\quad$ Ladná halt (PE7)

- Podivín station signals (PE8)

- Podivín station territory track signals (PE9)

- Podivín station switching system elements (PE10)

- Podivín station telecommunications elements (PE11)

- Podivín station electrical equipment elements (PE12)

- Level crossing at Podivín station (PE13)

- Railway crossing signals at Podivín station crossing (PE14).

3 Areal elements:

- Břeclav railway station (AE1)

- Podivín railway station (AE2)

- Crossing at Podivín station (AE3).

\section{Sub-process 2: Elements criticality analysis}

The criticality analysis of railway infrastructure on this section of track consisted of three stages: (Stage I) LEs criticality analysis; (Stage II) Point elements criticality analysis; and (Stage III) AEs criticality analysis.

\section{Stage I: LEs criticality analysis}

First, the identified LE1 line element was analysed. The underlying data were evaluated according to the relevant criteria for assessing line elements (L1-L4). The weighted criticality of the given element was determined according to equations (1) and (2). The results are presented in Table 5.

Table 5 Critical analysis of LEs on the Břeclav-Podivín track section

\begin{tabular}{lccccc}
\hline Criterion & $\begin{array}{c}\text { L1 Track } \\
\text { significance }\end{array}$ & $\begin{array}{c}\text { L2 Transport } \\
\text { performance }\end{array}$ & $\begin{array}{c}\text { L3 Alternative } \\
\text { route option }\end{array}$ & $\begin{array}{c}\text { L4 Risks of } \\
\text { the track }\end{array}$ & $\sum$ \\
\hline Criteria weight & 0.1 & 0.4 & 0.3 & 0.2 & \\
Simple criticality & 100 & 80 & 0 & 28.6 & \\
Weighted criticality & 10 & 32 & 0 & 5.7 & 47.7 \\
\hline
\end{tabular}

The assessed track section achieves $47.71 \%$ criticality.

\section{Stage II: Point elements criticality analysis}

In the next stage, the identified point elements PE1-PE14 were analysed. The underlying data were evaluated according to the relevant criteria for assessing point elements (P1-P4). The weighted criticality values for individual point elements were determined according to equations (1) and (2) and are presented in Table 6. 
Table 6 Criticality analysis of point elements on the Břeclav-Podivín track section

\begin{tabular}{lccccc}
\hline \multirow{2}{*}{ Element } & \multicolumn{5}{c}{ Simple criticality } \\
\cline { 2 - 5 } & $\begin{array}{l}\text { P1: Line } \\
\text { elements } \\
\text { criticality }\end{array}$ & $\begin{array}{c}\text { P2: Element } \\
\text { influence and } \\
\text { dependence }\end{array}$ & $\begin{array}{c}\text { P3: Element } \\
\text { substitutability }\end{array}$ & $\begin{array}{c}\text { P4: Element } \\
\text { risks }\end{array}$ & $\begin{array}{c}\text { Weighted } \\
\text { criticality }\end{array}$ \\
\cline { 1 - 4 } Criteria weight & 0.1 & 0.4 & 0.3 & 0.2 & \\
\hline PE1 & 47.7 & 50 & 90 & 72.2 & 66.2 \\
PE2 & 47.7 & 50 & 90 & 77.8 & 67.3 \\
PE3 & 47.7 & 60 & 100 & 66.7 & 72.1 \\
PE4 & 47.7 & 30 & 50 & 61.1 & 44.0 \\
PE5 & 47.7 & 40 & 90 & 50.0 & 57.8 \\
PE6 & 47.7 & 70 & 100 & 66.7 & 76.1 \\
PE7 & 47.7 & 20 & 20 & 50.0 & 28.8 \\
PE8 & 47.7 & 50 & 90 & 72.2 & 66.2 \\
PE9 & 47.7 & 50 & 90 & 77.8 & 67.3 \\
PE10 & 47.7 & 30 & 50 & 61.1 & 44.0 \\
PE11 & 47.7 & 40 & 90 & 50.0 & 57.8 \\
PE12 & 47.7 & 70 & 100 & 66.7 & 76.1 \\
PE13 & 47.7 & 20 & 10 & 38.9 & 23.5 \\
PE14 & 47.7 & 50 & 50 & 55.6 & 50.9 \\
\hline
\end{tabular}

Stage III: AEs criticality analysis

In the final stage, the identified areal elements AE1-AE3 were analysed. The underlying data were evaluated according to the relevant criteria for assessing areal elements (A1-A4). The weighted criticality values for individual AEs were determined according to equations (1) and (2) and are presented in Table 7.

Table 7 Critical analysis of AEs on the Břeclav-Podivín track section

\begin{tabular}{|c|c|c|c|c|c|}
\hline \multirow[b]{2}{*}{ Element } & \multicolumn{4}{|c|}{ Simple criticality } & \multirow{3}{*}{$\begin{array}{l}\text { Weighted } \\
\text { criticality }\end{array}$} \\
\hline & $\begin{array}{l}\text { A1: Line } \\
\text { elements } \\
\text { criticality }\end{array}$ & $\begin{array}{l}\text { A2: Point } \\
\text { elements } \\
\text { criticality }\end{array}$ & $\begin{array}{l}\text { A3: Element } \\
\text { complexity }\end{array}$ & $\begin{array}{c}\text { A4: } \\
\text { Alternative } \\
\text { route option }\end{array}$ & \\
\hline Criteria weight & 0.3 & 0.4 & 0.1 & 0.2 & \\
\hline $\mathrm{AE} 1$ & 47.7 & 69.7 & 100 & 100 & 72.2 \\
\hline AE2 & 47.7 & 63.8 & 80 & 0 & 47.8 \\
\hline AE3 & 47.7 & 37.2 & 20 & 0 & 31.2 \\
\hline
\end{tabular}


Figure 4 Assessed element categories on the track section between Břeclav and Podivín (see online version for colours)

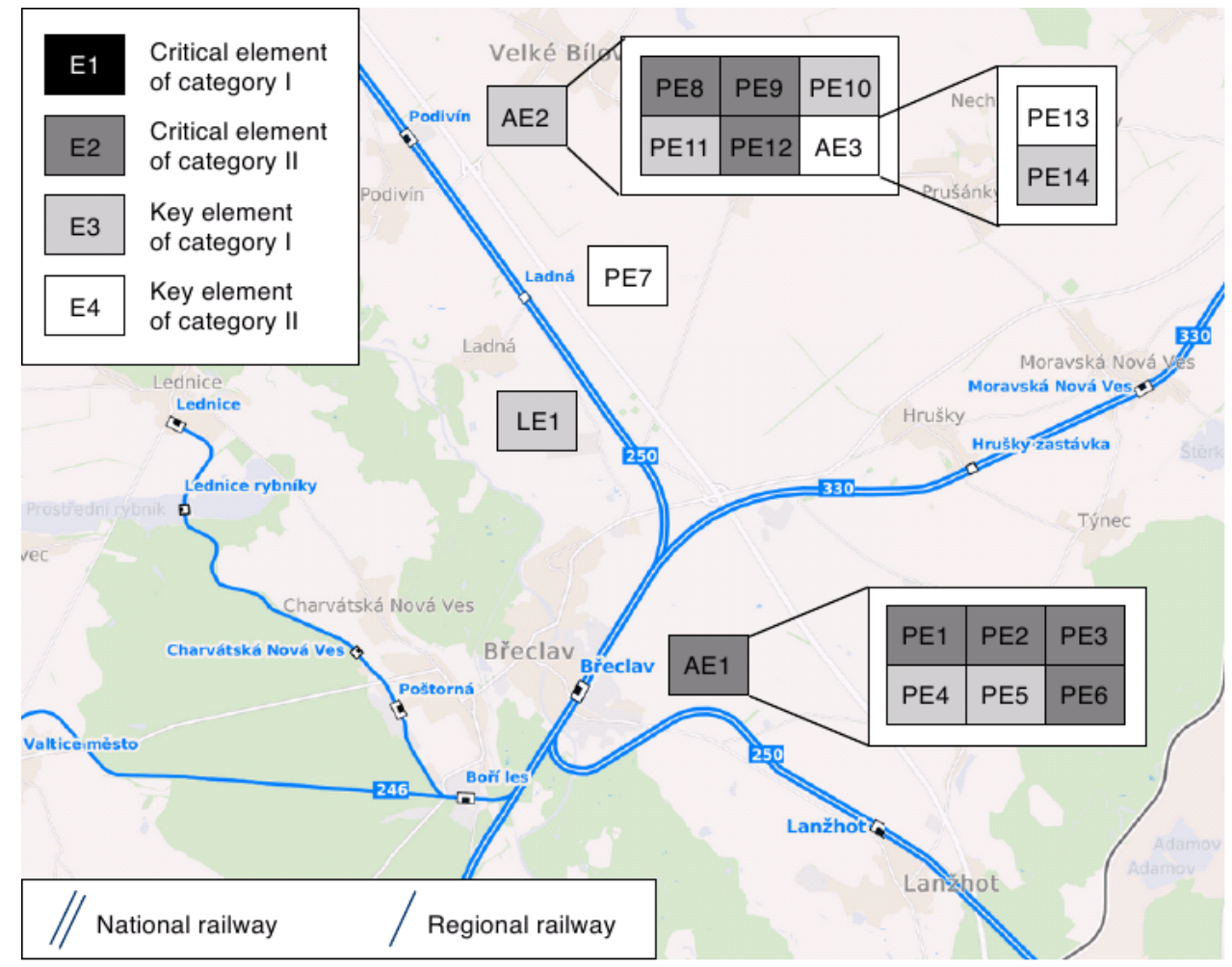

\section{Sub-process 3: Elements criticality assessment}

In the final sub-process, the resultant values of the weighted criticalities of the individual elements are compared to the boundary levels of criticality (Table 4) and classified according to the following four categories:

1 Critical elements of category I $(81 ; 100)$ :

- no element has been included in this category.

2 Critical elements of category II $(62 ; 81)$ :

- Břeclav station signals (PE1)

- Břeclav station territory track signals (PE2)

- Břeclav station traffic control workplace (PE3)

- Břeclav station electrical equipment elements (PE6)

- $\quad$ Podivín station signals (PE8) 
- Podivín station territory track signals (PE9)

- Podivín station electrical equipment elements (PE12)

- Břeclav railway station (AE1).

3 Key elements of category I $(43 ; 62)$ :

- Břeclav - Podivín intermediate section (LE1)

- Břeclav station switching system elements (PE4)

- Břeclav station telecommunications elements (PE5)

- Podivín station switching system elements (PE10)

- Podivín station telecommunications elements (PE11)

- Railway crossing signals at Podivín station crossing (PE14)

- Podivín railway station (AE2).

4 Key elements of category II $(0 ; 43)$ :

- $\quad$ Ladná halt (PE7)

- Level crossing at Podivín station (PE13)

- Crossing at Podivín station (AE3).

From the results of the case study, the following were clearly identified on the assessed section of track: eight critical elements of category 2, seven key elements of category 1 and three key elements of category 2. A graphical representation of the assessment results is presented in Figure 4.

\section{Discussion}

In the previous sections of the article, key factors determining and influencing criticality were identified. These factors were subsequently taken into account in the proposed RICA tool, which allows an integrated assessment of the criticality of railway infrastructure elements. An example of the practical application of the proposed tool was subsequently presented as a case study. The aim of this part of the article is to discuss the benefit and added value of the proposed RICA tool compared to existing tools and methods.

To this end, five tools and methods were selected to assess the criticality of rail infrastructure, which are by their approach closest to the proposed RICA tool:

- method for identifying and ranking critical components and sets of components in technical infrastructures (Jönsson et al., 2008)

- infrastructure interdependencies simulator (i2Sim) (Alsubaie et al., 2015)

- framework for assessing the vulnerability of rail freight networks by introducing two bi-level models (Bababeik et al., 2017)

- $\quad$ procedure for identifying potential CI elements in the railway sub-sector (Leitner et al., 2017)

- methodology for identifying critical infrastructure objects in transport (Dvorak et al., 2017). 
Table 8 Comparative analysis of the usability of selected instruments and methods for integral critical evaluation of railway infrastructure elements

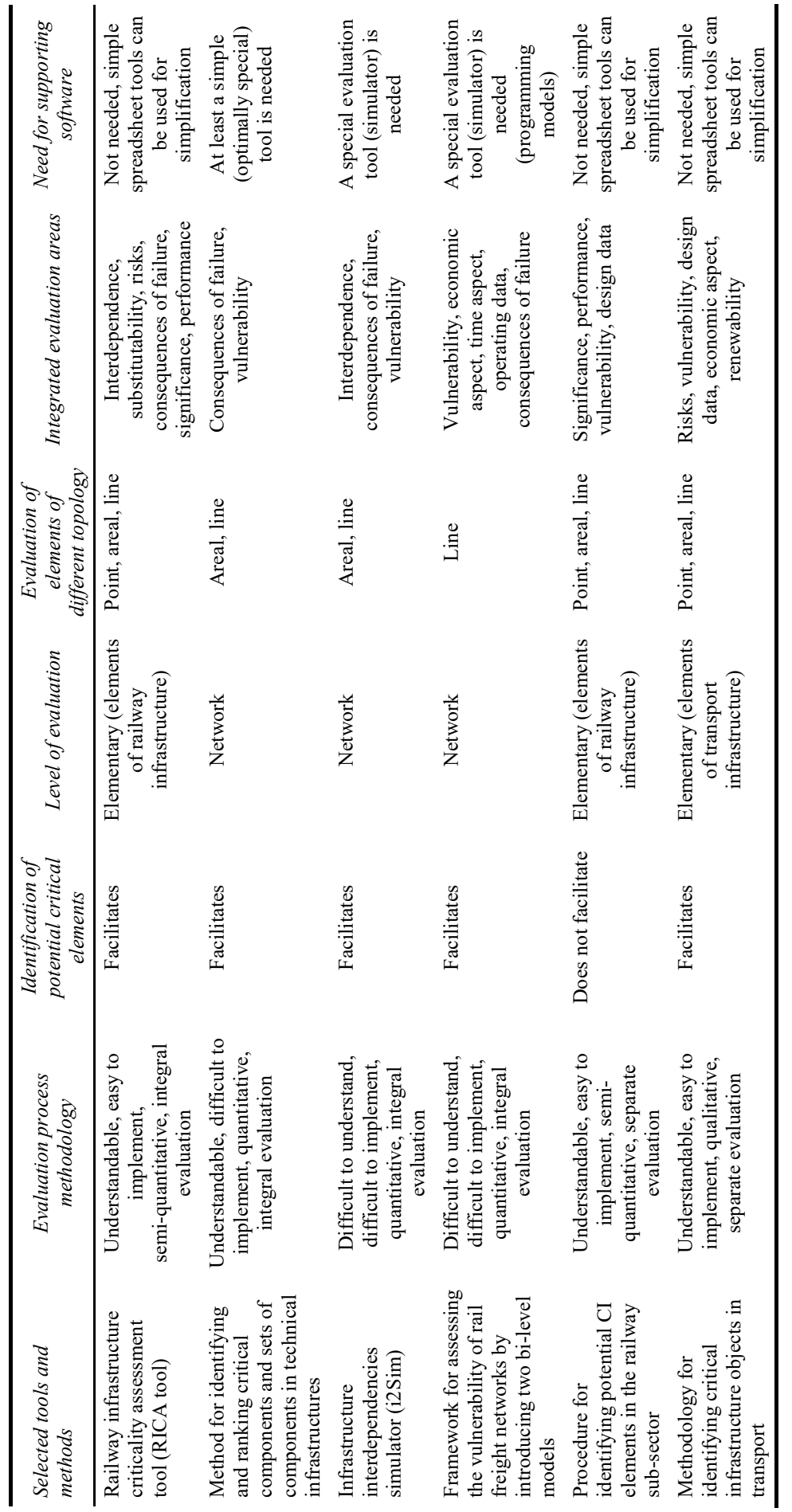


The above tools and methods were compared using a set of criteria reflecting defined evaluation conditions, i.e., by taking into account the key factors determining and influencing the criticality assessment of all elements of the railway infrastructure. For this purpose, the following comparative criteria were set:

- $\quad$ evaluation process methodology

- identification of potential critical elements

- level of evaluation

- evaluation of elements of different topology

- integrated evaluation areas

- $\quad$ need for supporting software.

On the basis of these criteria, a comparative analysis of the selected tools and methods was performed. Attention was given to the accessibility, complexity and practical application of these tools and methods. The results of the comparative analysis are presented in Table 8 .

From the results of the comparative analysis it is clear that the presented methods differ from each other especially in terms of their demandingness, specificity and complexity of application. Although all methods deal with evaluating critical elements in railway infrastructure, the individual approaches are so different that they cannot be effectively compared to each other. For example, methods that allow integral evaluation (i.e., Jönsson et al., 2008; Alsubaie et al., 2015; Bababeik et al., 2017) only access evaluation in a networked manner and require the use of specific software tools, whereas methods allowing elementary evaluation (i.e., comprehensive evaluation of point, areal and LEs) only approach evaluation in a separate manner and thus do not take into account all factors (i.e., Leitner et al., 2017; Dvorak et al., 2017).

Based on this observation, it can be stated that the proposed RICA Tool successfully fills a research gap in the methodology for evaluating the criticality of railway infrastructure elements. The method is comprehensible, easy to implement, and allows integral assessment at an elementary level.

\section{Conclusions}

Assessing critical elements to subsequently identify and protect them is now an integral part of the railway transport safety process. A cyclical application not only ensures the continuous assessment of critical elements but also highlights security measures already implemented or new risks.

The RICA tool uses an integral approach consisting of a comprehensive assessment of the technical and process factors in rail transport. The criticality of railway infrastructure elements is thus assessed not only in terms of the relevance and resilience of those elements but also their interdependence, substitutability, risk and impact. This tool permits criticality to be comprehensively assessed and provides continuous correlation between the assessed elements of various topological structures, i.e., line, point and AEs. 
The RICA Tool is specific in that it allows a sequential assessment of criticality. The essence of this assessment method is to take into account the functional links between individual groups of elements. Analysis of criticality in railway infrastructure elements is thus performed in three stages, each being conditional on the previous stage. Stage I assesses LEs forming the basic level of infrastructure. In stage II, point elements that support and whose function is bound to LEs are then evaluated. To factor in the link between line and point elements, the results of the previous assessment stage are always reflected in the following stage. Similarly, links are considered in the function of AEs. Sequential assessment therefore allows assessment to be completed at the end of any stage, but must always be performed beginning with LEs, then point elements and finally AEs.

\section{Acknowledgements}

The article was elaborated within a Ministry of the Interior of the Czech Republic Project, filed under: VI20152019049, entitled 'Dynamic Resilience Evaluation of Interrelated Critical Infrastructure Subsystems'.

\section{References}

Agency for Railways (2016) Common Safety Methods [online] https://www.era.europa.eu/ activities/common-safety-methods_en (accessed 16 November 2018).

Alsubaie, A., Alutaibi, K. and Marti, J.R. (2015) 'A Methodology for Identifying Critical Components in Physical Infrastructures', EIC Climate Change Technology Conference (CCTC 2015), Paper No. 1570044301, The Canadian Academy of Engineering, Ottawa, Canada.

Bababeik, M., Nasiri, M.M., Khademi, N. and Chen, A. (2017) 'Vulnerability evaluation of freight railway networks using a heuristic routing and scheduling optimization model', Transportation, Vol. 44, No. 5, pp.1-28, DOI: 10.1007/s11116-017-9815-x.

Caetano, V., Couto, P., Fontul, S. and Silva, M.J.F. (2018) 'Multi-criteria analysis applied to railway rehabilitation', in MATEC Web of Conferences, Vol. 211, Paper No. 12007, DOI: $10.1051 /$ matecconf $/ 201821112007$.

Celko, M. and Dvorak, Z. (2018) 'Update criteria for critical bridge objects in railway transport subsector', 23rd International Conference 'Solving Crisis Situations in a Specific Environment, pp.88-97, University of Zilina, Zilina, Slovakia.

CRIA (2016) Crisis Preparedness Plan of a Critical Infrastructure Subject, Czech Railway Infrastructure Administration, Prague, Czech Republic.

Czech Railways (2018) Maps of Czech Railways [online] https://old.cd.cz/mapa (accessed 30 November 2018).

Dvorak, Z., Luskova, M., Hruza, P. and Sousek, R. (2013) 'Complex automated information system for remote management of crisis situations in rail transport', Communications Scientific Letters of the University of Zilina, Vol. 15, No. 3, pp.83-88.

Dvorak, Z., Sousek, R., Sventekova, E., Leitner, B. and Cizlak, M. (2010) Risk Management in Railway Transport, Jan Perner Institute, Pardubice, Czech Republic.

Dvorak, Z., Sventekova, E., Rehak, D. and Cekerevac, Z. (2017) 'Assessment of critical infrastructure elements in transport', Procedia Engineering, Vol. 187, pp.548-555, DOI: 10.1016/j.proeng.2017.04.413. 
European Council (2008) Council Directive 2008/114/EC of 8 December 2008 on the Identification and Designation of European Critical Infrastructures and the Assessment of the Need to Improve their Protection, Brussels, Belgium.

Faramondi, L., Oliva, G., Pascucci, F., Panzieri, S. and Setola, R. (2016) 'Critical node detection based on attacker preferences', in 24th Mediterranean Conference on Control and Automation (MED), Paper No. 16212498, IEEE, Athens, Greece, DOI: 10.1109/MED.2016.7535859.

Fekete, A. (2018) Urban Disaster Resilience and Critical Infrastructure, Julius-MaximiliansUniversität Würzburg, Würzburg, Germany.

Fourie, C.J. and Zhuwaki, N.T. (2017) 'A modelling framework for railway infrastructure reliability analysis', South African Journal of Industrial Engineering, Vol. 28, No. 4, pp.150-160, DOI: 10.7166/28-4-1763.

Gasparik, J. and Kolar, J. (2017) Railway Transport: Technology, Management, Train Diagram and Other 100 Interests, Grada Publishing, Prague, Czech Republic.

Hedel, R., Boustras, G., Gkotsis, I., Vasiliadou, I. and Rathke, P. (2018) 'Assessment of the european programme for critical infrastructure protection in the surface transport sector', International Journal of Critical Infrastructures, Vol. 14, No. 4, pp.311-335, DOI: 10.1504/IJCIS.2018.095616.

Hromada, M. and Lukas, L. (2012) 'Multicriterial evaluation of critical infrastructure element protection in Czech Republic', in International Conferences ASEA and DRBC 2012, pp.361-368, Springer-Verlag, Berlin, Germany.

IEC (2006) IEC 60812:2006, Analysis Techniques for System Reliability - Procedure for Failure Mode and Effects Analysis (FMEA), International Electrotechnical Commission, Geneva, Switzerland.

Johansson, J., Hassel, H. and Cedergren, A. (2011) 'Vulnerability analysis of interdependent critical infrastructures: case study of the Swedish railway system', International Journal of Critical Infrastructures, Vol. 7, No. 4, pp.289-316, DOI: 10.1504/IJCIS.2011.045065.

Jönsson, H., Johansson, J. and Johansson, H. (2008) 'Identifying critical components in technical infrastructure networks', Journal of Risk and Reliability, Vol. 222, No. 2, pp.235-243, DOI: 10.1243/1748006XJRR138.

Katina, P.F. and Hester, P.T. (2013) 'Systemic determination of infrastructure criticality', International Journal of Critical Infrastructures, Vol. 9, No. 3, pp.211-225, DOI: 10.1504/IJCIS.2013.054980.

Khaled, A.A., Jin, M., Clarke, D.B. and Hoque, M.A. (2015) 'Train design and routing optimization for evaluating criticality of freight railroad infrastructures', Transportation Research Part B: Methodological, Vol. 71, pp.71-84, DOI: 10.1016/j.trb.2014.10.002.

Klein, P. and Hutter, R. (2017) 'Qualitative criteria in the assessment of security measures for critical infrastructure protection - a new approach', International Journal of Critical Infrastructures, Vol. 13, No. 1, pp.29-45, DOI: 10.1504/IJCIS.2017.083637.

Leitner, B., Mocova, L. and Hromada, M. (2017) 'A new approach to identification of critical elements in railway infrastructure', Procedia Engineering, Vol. 187, pp.143-149, DOI: 10.1016/j.proeng.2017.04.360.

Luiijf, E., Burger, H. and Klaver, M. (2003) 'Critical infrastructure protection in the Netherlands', in Gattiker, U.E. (Ed.): EICAR Conference Best Paper Proceedings, European Institute for Computer Anti-Virus Research, Copenhagen, Denmark.

Luskova, M., Dvorak, Z. and Leitner, B. (2015) 'Impact of extreme weather events on land transport infrastructure', in 19th International Scientific Conference on 'Transport Means', pp.306-309, Kaunas University of Technology, Kaunas, Lithuania.

Maalel, A., Mejri, L., Hadj-Mabrouk, H. and Ghezala, H.B. (2014) 'Towards a decision support system for security analysis application to railroad accidents', Lecture Notes in Business Information Processing, Vol. 196, pp.46-56.

Ministry of Transport (2013) Transport Policy of the Czech Republic for the period 2014-2020 with a view to 2050, Ministry of Transport of the Czech Republic, Prague, Czech Republic. 
Norkin, V.I., Gaivoronski, A.A., Zaslavsky, V.A. and Knopov, P.S. (2018) 'Models of the optimal resource allocation for the critical infrastructure protection', Cybernetics and Systems Analysis, Vol. 54, No. 5, pp.696-706, DOI: 10.1007/s10559-018-0071-7.

Pant, R., Blainey, S.P., Hall, J.W. and Preston, J. (2015) 'Assessing risks to inform resilience: a criticality assessment of the British railway network', in Dolan, T. and Collins, B. (Eds.): International Symposium for Next Generation Infrastructure Conference Proceedings, pp.117-121, UCL STEaPP, London, United Kingdom.

Pant, R., Hall, J.W. and Blainey, S.P. (2016) 'Vulnerability assessment framework for interdependent critical infrastructures: case-study for Great Britain's rail network', European Journal of Transport and Infrastructure Research, Vol. 16, No. 1, pp.174-194.

Rehak, D., Hromada, M. and Novotny, P. (2016) 'European critical infrastructure risk and safety management', Chemical Engineering Transactions, Vol. 48, pp.943-948, DOI: $10.3303 /$ CET1648158.

Rehak, D., Senovsky, P. and Slivkova, S. (2018) 'Resilience of critical infrastructure elements and its main factors', Systems, Vol. 6, No. 2, Article No. 21. DOI: 10.3390/systems6020021.

Rehak, D., Senovsky, P., Hromada, M. and Lovecek, T. (2019) 'Complex approach to assessing resilience of critical infrastructure elements', International Journal of Critical Infrastructure Protection, Vol. 25, pp.125-138, DOI: 10.1016/j.ijcip.2019.03.003.

Rinaldi, S.M., Peerenboom, J.P. and Kelly, T.K. (2001) 'Identifying, understanding and analyzing critical infrastructure interdependencies’, IEEE Control Systems Magazine, Vol. 21, No. 6, pp.11-25, DOI: 10.1109/37.969131.

Slivkova, S., Rehak, D. and Novotny, P. (2018) 'Critical element designation system in rail transport in the Czech Republic', Chemical Engineering Transactions, Vol. 67, pp.775-780, DOI: $10.3303 /$ CET1867130.

Sousek, R. and Dvorak, Z. (2013) 'Methods for processing type threats in railway transport', in 17th International Scientific Conference 'Transport Means 2013', pp.278-281, Kaunas University of Technology, Kaunas, Lithuania.

Stoller, J., Dvorak, P., Turo, T. and Zezulova, E. (2018) 'Basic principles of critical infrastructure protection', in 22nd International Scientific Conference 'Transport Means 2018', pp.267-271, Kaunas University of Technology, Kaunas, Lithuania.

Striegler, R., Ambros, J., Janoska, Z., Pokorny, P., Striegler, R., Senk, P. and Valentova, V. (2012) Identification of Critical Locations on Roads in Extravilanes, The Transport Research Centre, Brno, Czech Republic.

Theoharidou, M., Kotzanikolaou, P. and Gritzalis, D. (2009) 'Risk-based criticality analysis', in Palmer, C. and Shenoi, S. (Eds.): Critical Infrastructure Protection III. ICCIP 2009. IFIP Advances in Information and Communication Technology, Vol. 311, pp.35-49, Springer, Berlin, Germany, DOI: 10.1007/978-3-642-04798-5_3.

Vlkovsky, M., Ivanusa, T., Neumann, V., Foltin, P. and Vlachova, H. (2017) 'Optimizating cargo security during transport using dataloggers', Journal of Transportation Security, Vol. 10, Nos. 3-4, pp.63-71, DOI: 10.1007/s12198-017-0179-4.

Zhang, Z., Li, X. and Li, H. (2015) 'A quantitative approach for assessing the critical nodal and linear elements of a railway infrastructure', International Journal of Critical Infrastructure Protection, Vol. 8, pp.3-15, DOI: 10.1016/j.ijcip.2014.11.001. 